\title{
Cavity Formation Modeling of Fiber Fuse in Single-Mode Optical Fibers
}

\author{
Yoshito Shuto \\ Ofra Project, Iruma 358-0023, Japan \\ Correspondence should be addressed to Yoshito Shuto; ofra@tuba.ocn.ne.jp
}

Received 19 March 2017; Accepted 19 April 2017; Published 14 May 2017

Academic Editor: Vasily Spirin

Copyright (C) 2017 Yoshito Shuto. This is an open access article distributed under the Creative Commons Attribution License, which permits unrestricted use, distribution, and reproduction in any medium, provided the original work is properly cited.

\begin{abstract}
The evolution of a fiber-fuse phenomenon in a single-mode optical fiber was studied theoretically. To clarify both the silica-glass densification and cavity formation, which have been observed in fiber fuse propagation, we investigated a nonlinear oscillation model using the Van Der Pol equation. This model was able to phenomenologically explain both the densification of the core material and the formation of periodic cavities in the core layer as a result of a relaxation oscillation.
\end{abstract}

\section{Introduction}

Owing to the progress of dense wavelength division multiplexing (DWDM) technology using an optical-fiber amplifier, we can exchange large amounts of data at a rate of over $60 \mathrm{Tbit} / \mathrm{s}$ [1]. However, it is widely recognized that the maximum transmission capacity of a single strand of fiber is rapidly approaching its limit of about $100 \mathrm{Tbit} / \mathrm{s}$ owing to the optical power limitations imposed by the fiberfuse phenomenon and the finite transmission bandwidth determined by optical-fiber amplifiers [2]. To overcome these limitations, space-division multiplexing (SDM) technology using a multicore fiber (MCF) was proposed [3, 4], and $1 \mathrm{Pbit} / \mathrm{s}$ transmission was demonstrated by using a lowcrosstalk 12-core fiber [5].

The fiber-fuse phenomenon was first observed in 1987 by British scientists [6-9]. Several review articles [10-14] have been recently published that cover many aspects of the current understanding of fiber fuses.

A fiber fuse can be generated by bringing the end of a fiber into contact with an absorbent material or melting a small region of a fiber using an arc discharge of a fusion splice machine $[6,15,16]$. If a fiber fuse is generated, an intense bluewhite flash occurs in the fiber core, and this flash propagates along the core in the direction of the optical power source at a velocity on the order of $1 \mathrm{~m} / \mathrm{s}$. The temperature and pressure in the region, where this flash occurs, have been estimated to be about $10^{4} \mathrm{~K}$ and $10^{4}$ atmospheres, respectively [17]. Fuses are terminated by gradually reducing the laser power to a termination threshold at which the energy balance in the fuse is broken.

The critical diameter $d_{\mathrm{cr}}$, which is usually larger than the core diameter $2 r_{c}$, is a characteristic dimensional parameter of the fiber fuse effect. In an inner area with diameter $d \leq d_{\mathrm{cr}}$, a fiber fuse (high-temperature plasma) propagates and silica glass is melted [17]. $d_{\mathrm{cr}}$, defined as the diameter of the melting area, is considered as the radial size of the plasma generated in the fiber fuse [18]. Dianov et al. reported that the refractive index of the inner area with $d \leq d_{\text {cr }}$ in Ge-doped and/or pure silica core fibers is increased by silica-glass densification and/or the redistribution of the dopant (Ge) [19].

When a fiber fuse is generated, the core layer in which the fuse propagates is seriously damaged, and the damage has the form of periodic or nonperiodic bullet-shaped cavities remaining in the core [20-28] (see Figure 1). Needless to say, the density in a cavity is lower than that of the neighboring silica glass. It has been found that molecular oxygen is released and remains in the cavities while maintaining a high pressure (about 4 atmospheres [7] or 5-10 atmospheres [19]) at room temperature. Recently, several types of sensors based on periodic cavities have been proposed as a cost-effective approach to sensor production [26-28]. 


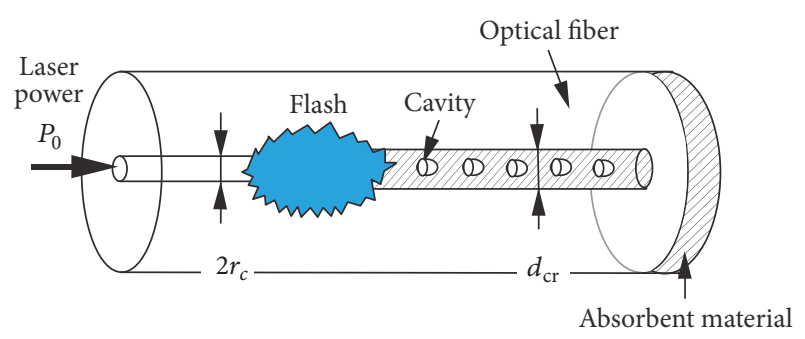

FIGURE 1: Schematic view of damaged optical fiber.

The dynamics of cavity formation have been investigated since the discovery of the fiber-fuse phenomenon. Kashyap reported that the cavity shape was dependent on the nature of the input laser light (CW or pulses) when the average input power was maintained at $2 \mathrm{~W}$ [7]. When CW light was input, the cavities appeared to be elliptical and cylindrically symmetric. On the other hand, short asymmetric cavities were formed by injecting (mode-locked) pulses with $100 \mathrm{ps}$ FWHM (full width at half maximum), while long bulletshaped cavities were observed by injecting pulses with $190 \mathrm{ps}$ FWHM [7]. Dianov and coworkers observed the formation of periodic bullet-shaped cavities $20-70 \mu$ s after the passage of a plasma leading edge $[29,30]$. Todoroki classified fiberfuse propagation into three modes (unstable, unimodal, and cylindrical) according to the plasma volume relative to the pump beam size [25]. When the pump power was increased or decreased rapidly, the increment in length of the void-free segment or the occurrence of an irregular void pattern was observed, respectively [25].

These cavities have been considered to be the result of either the classic Rayleigh instability caused by the capillary effect in the molten silica surrounding a vaporized fiber core [31] or the electrostatic repulsion between negatively charged layers induced at the plasma-molten silica interface $[32,33]$. Although the capillary effect convincingly explains the formation mechanism of water droplets from a tap and/or bubbles through a water flow, this effect does not appear to apply to the cavity formation mechanism of a fiber fuse owing to the anomalously high viscosity of the silica glass $[22,32]$. Yakovlenko proposed a novel cavity formation mechanism based on the formation of an electric charge layer on the interface between the liquid glass and plasma [32]. This charge layer, where the electrons adhere to the liquid glass surface, gives rise to a "negative" surface tension coefficient for the liquid layer. In the case of a negative surface tension coefficient, the deformation of the liquid surface proceeds, giving rise to a long bubble that is pressed into the liquid [32]. Furthermore, an increase in the charged surface due to the repulsion of similar charges results in the development of instability [32]. The instability emerges because the countercurrent flowing in the liquid causes the liquid to enter the region filled with plasma, and the extruded liquid forms a bridge. Inside the region separated from the front part of the fuse by this bridge, gas condensation and cooling of the molten silica glass occur [33]. A row of cavities is formed by the repetition of this process. Although Yakovlenko's explanation of the formation of a long cavity and

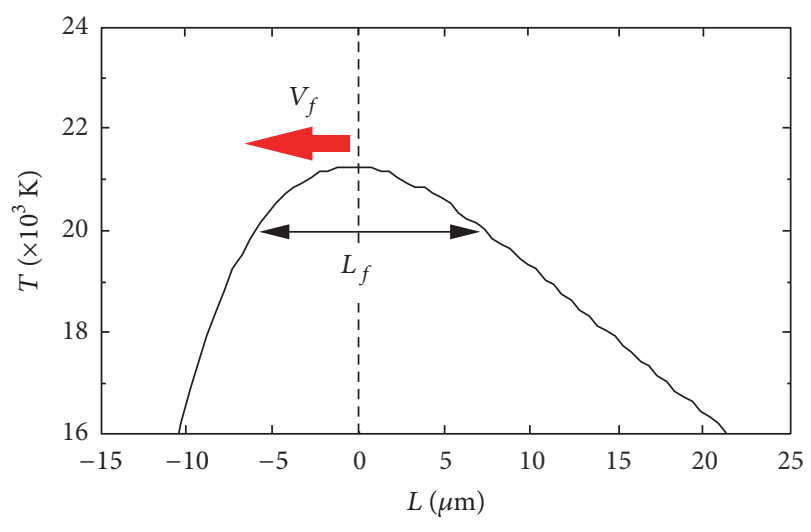

FIGURE 2: Temperature distribution of the high-temperature front versus the length along the $z$ direction at $t=2 \mathrm{~ms}$ after the incidence of $1.8 \mathrm{~W}$ laser light $\left(\lambda_{0}=1.48 \mu \mathrm{m}\right)$ for the initial attenuation IA $=$ $8 \mathrm{~dB}$. The center of the high-temperature front is set at $L=0 \mu \mathrm{m}$.

rows of cavities is very interesting, the concept of "negative" surface tension appears to be unfeasible in the field of surface science and/or plasma physics (see Appendix A).

Low-frequency plasma instabilities are triggered by moving the high-temperature front of a fiber fuse toward the light source. It is well known that such a low-frequency plasma instability behaves as a Van Der Pol oscillator with instability frequency $\omega_{0}$ [34-52].

Therefore, the oscillatory motion of the ionized gas plasma during fiber-fuse propagation can be studied phenomenologically using the Van Der Pol equation [53]. In this paper, the author describes a novel nonlinear oscillation model using the Van Der Pol equation and qualitatively explains both the silica-glass densification and cavity formation observed in fiber-fuse propagation.

\section{Nonlinear Oscillation Behavior in Ionized Gas Plasma}

An ionized gas plasma exhibits oscillatory motion with a small amplitude when the high-temperature front of a fiber fuse propagates toward the light source.

The frequency $\omega_{0}$ of the oscillation of the gas plasma is determined by the fiber-fuse propagation velocity $V_{f}$ and the free-running distance $L_{f}$ of the oscillator in the front region of the plasma and is given by

$$
\omega_{0}=2 \pi \frac{2 V_{f}}{L_{f}} .
$$

The plasma instability is enhanced in the vicinity of the high-temperature peak. Therefore, in this study, the author estimated $L_{f}$ from the calculated temperature distribution of the high-temperature front of an ionized gas plasma. Figure 2 shows the temperature distribution of the high-temperature front as a function of the length $L$ along the $z$ direction. The calculation of the temperature distribution was described in [54]. In Figure 2, an initial attenuation IA of $8 \mathrm{~dB}$ corresponds to an optical absorption coefficient $\alpha$ of $1.84 \times 10^{6} \mathrm{~m}^{-1}$ when 


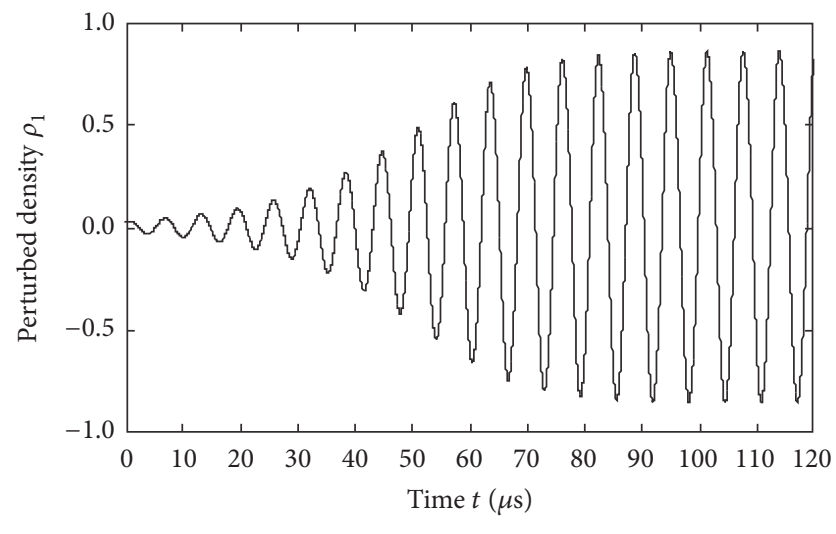

FIgURE 3: Time dependence of the perturbed density during fiberfuse propagation. $\epsilon=0.1 ; \beta=6.5$.

the thickness of the absorption layer, which consists of carbon black, is about $1 \mu \mathrm{m}$ [54]. As shown in Figure 2, $L_{f}$ was estimated to be about $12.5 \mu \mathrm{m}$, where $V_{f}=1 \mathrm{~m} / \mathrm{s}$ was used in the calculation.

Here, the density $\rho$ is considered in the form $\rho=\rho_{0}+\rho_{1}$, where $\rho_{0}$ is the initial density of the stationary (unperturbed) part in the front region of the plasma and $\rho_{1}$ is the perturbed density. The dynamical behavior of $\rho_{1}$ resulting from fiberfuse propagation can be represented by the Van Der Pol equation:

$$
\frac{d^{2} \rho_{1}}{d t^{2}}-\epsilon\left(1-\beta \rho_{1}^{2}\right) \frac{d \rho_{1}}{d t}+\omega_{0}^{2} \rho_{1}=0,
$$

where $\epsilon$ is a parameter that characterizes the degree of nonlinearity and $\beta$ characterizes the nonlinear saturation (see Appendix B).

The oscillatory motion for $\epsilon=0.1$ and $\beta=6.5$ is shown in Figure 3, where the perturbed density $\rho_{1}$ is plotted as a function of time. When $t \geq 80 \mu \mathrm{s}$, the maximum and minimum values of $\rho_{1}$ for the ionized gas plasma reach 0.86 and -0.86 , respectively. The maximum value $(0.86)$ means that the increase in density of the core material reaches $86 \%$, which is almost equal to the experimental value (87\%) estimated by Dianov et al. [19].

On the other hand, it can be seen that for $\epsilon=0.1$ the motion of the Van Der Pol oscillator is very nearly harmonic, exhibiting alternate compression and rarefaction of the density with a relatively small period $\Phi$ of about $6.3 \mu \mathrm{s}$.

Next, the oscillatory motion for $\epsilon=5,9$, and 14 with $\beta=$ 6.5 was examined. The calculated results are shown in Figures $4-6$, respectively.

It can be seen that, for $\epsilon=5,9$, and 14 , the oscillations consist of sudden transitions between compressed and rarefied regions. This type of motion is called a relaxation oscillation [53], and the term "self-excited oscillation" is also often used.

The $\Phi$ values of the motion corresponding to $\epsilon=5,9$, and 14 were estimated to be about $12.9,21.6$, and $36.1 \mu \mathrm{s}$, respectively. These $\Phi$ values are much larger than those for $\epsilon=0.1$.

The oscillatory motion generated in the high-temperature front of the ionized gas plasma can be transmitted to the

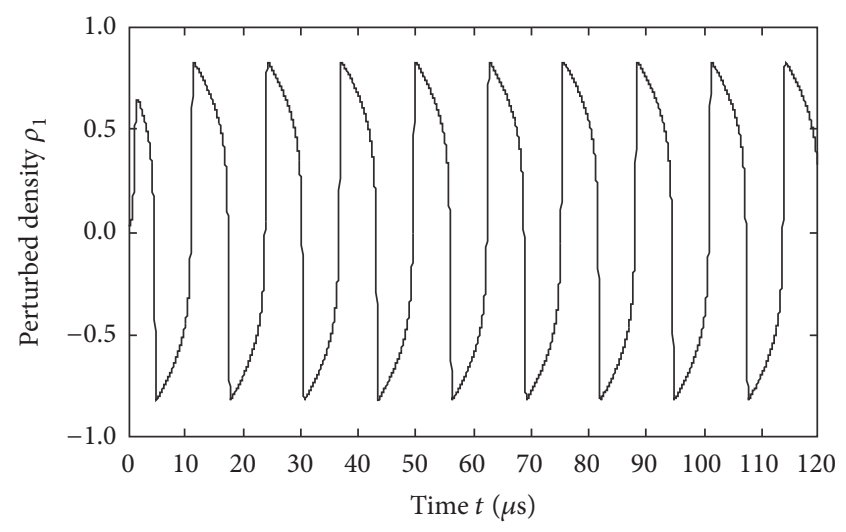

FIGURE 4: Time dependence of the perturbed density during fiberfuse propagation. $\epsilon=5 ; \beta=6.5$.

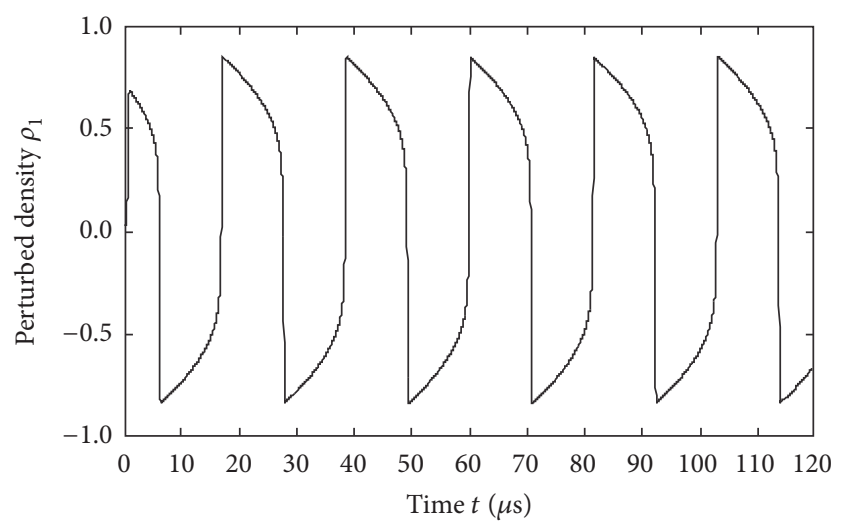

FIGURE 5: Time dependence of the perturbed density during fiberfuse propagation. $\epsilon=9 ; \beta=6.5$.

neighboring plasma at the rate of $V_{f}$ when the fiber fuse propagates toward the light source. Figure 7 shows schematic view of the dimensional relationship between the temperature and the perturbed density of the ionized gas plasma during fiber-fuse propagation. In Figure $7, \Lambda$ is the interval between the periodic compressed (or rarefied) parts.

The relationship between the period $\Phi$ and the interval $\Lambda$ is

$$
\Lambda=\Phi V_{f} .
$$

The $\Lambda$ values of the motion corresponding to $\epsilon=5,9$, and 14 are thus estimated to be about 12.9, 21.6, and $36.1 \mu \mathrm{m}$, respectively, using (3) and $V_{f}=1 \mathrm{~m} / \mathrm{s}$. If a large amount of molecular oxygen $\left(\mathrm{O}_{2}\right)$ accumulates in the rarefied part, the periodic formation of bubbles (or voids) will be observed. In such a case, $\Lambda$ is equal to the periodic void interval. The estimated $\Lambda$ values $(12.9,21.6$, and $36.1 \mu \mathrm{m})$ are close to the experimental periodic void intervals of $13-22 \mu \mathrm{m}$ observed in fiber-fuse propagation $[22,55]$.

Figure 8 shows the relationship between $\Phi$ and the nonlinearity parameter $\epsilon$. As shown in Figure 8 , $\Phi$, which is proportional to the interval $\Lambda$, increases with increasing $\epsilon$. That is, the increase in $\Phi$ and/or $\Lambda$ occurs because of the enhanced nonlinearity. It was found that the experimental 


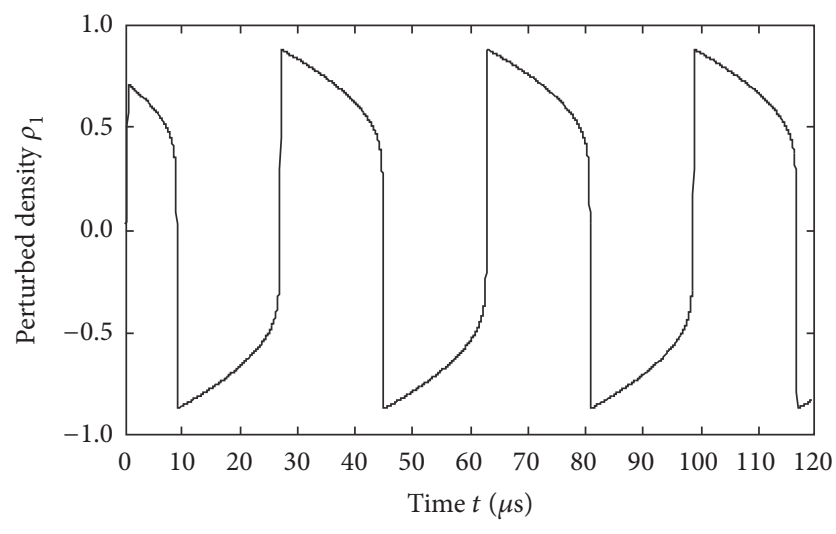

FIGURE 6: Time dependence of the perturbed density during fiberfuse propagation. $\epsilon=14 ; \beta=6.5$.

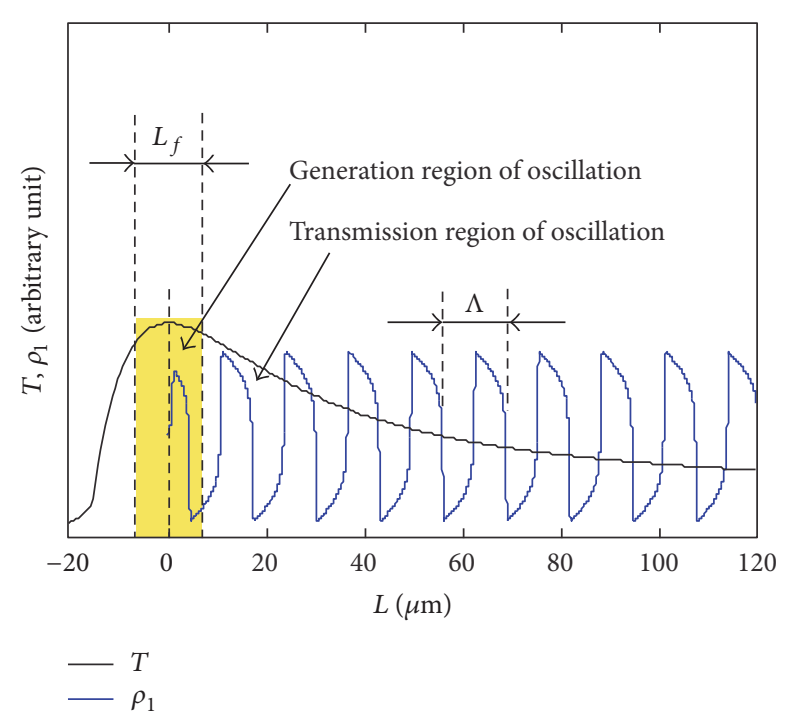

FIGURE 7: Schematic view of the dimensional relationship between the temperature and the perturbed density of the ionized gas plasma during fiber-fuse propagation.

periodic void interval increases with the laser pump power $[22,55]$. It can therefore be presumed that the nonlinearity of the Van Der Pol oscillator occurring in the ionized gas plasma is enhanced with increasing pump power.

Kashyap reported that the cavity shape was dependent on the nature of the input laser light (CW or pulses) [7]. Todoroki classified the damage to the front part of a fiber fuse into three shapes (two spheroids and a long partially cylindrical void) depending on the pump power [22]. He also found that fast increment or decrement of the pump power results in the increment in length of the void-free segment or the occurrence of an irregular void pattern, respectively [25]. These findings indicate that the void shape and the regularity of the void pattern may be determined by the degree of nonlinearity of the Van Der Pol oscillator.

In what follows, the author describes an examination result about the relationship between the interval $\Lambda$ and the input laser power $P_{0}$ observed in fiber-fuse propagation.

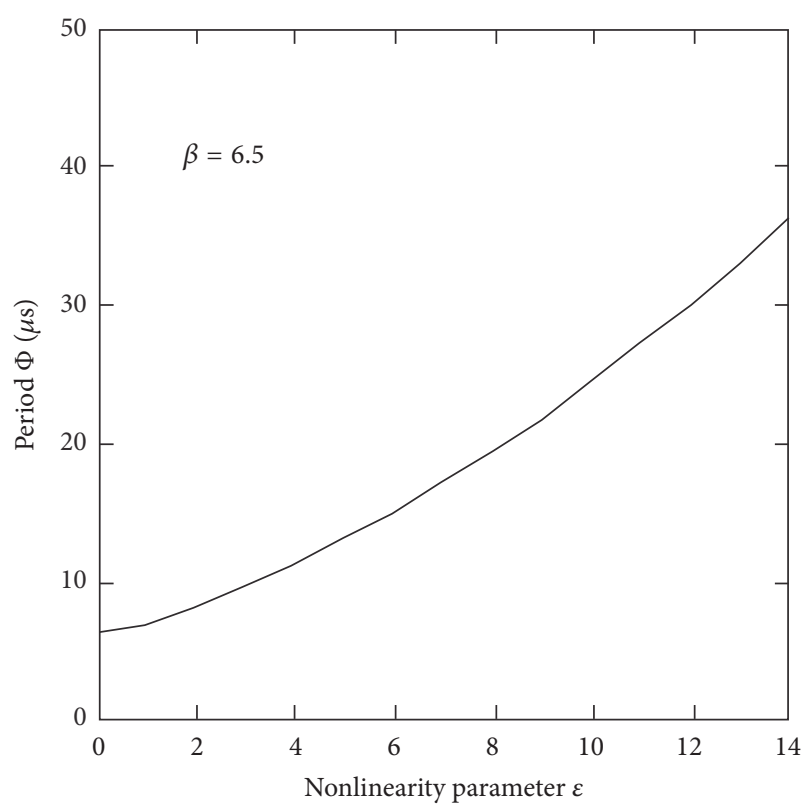

FIGURE 8: Relationship between the period $\Phi$ and the nonlinearity parameter $\epsilon . \beta=6.5$.

2.1. Power Dependence of Periodic Void Interval. It is well known that the fiber-fuse propagation velocity $V_{f}$ increases with increasing the input laser power $P_{0}[7,8,21,22,24,25$, 56-58]. Furthermore, in addition to $V_{f}$, Todoroki reported the $P_{0}$ dependence of $\Lambda$ in a SMF-28e fiber at $\lambda_{0}=1.48 \mu \mathrm{m}$ $[22,55]$.

In this study, the author investigated the $P_{0}$ dependence of $\Lambda$ using the experimental $V_{f}$ values $[22,25]$ and the calculated $\Phi$ values shown in Figure 8.

To explain the experimental $\Lambda$ values in the $P_{0}$ range from the threshold power $\left(P_{\text {th }} \simeq 1.3 \mathrm{~W}[59]\right)$ to $9 \mathrm{~W}, \Lambda\left(P_{0}\right)$ can be represented by the following equation:

$$
\Lambda\left(P_{0}\right)=\Phi_{0} V_{f}\left(P_{0}\right)\left[1-\gamma \frac{\sqrt{\Phi_{n}(\epsilon)-\Phi_{n}(\epsilon=0)}}{\Phi_{0}}\right]
$$

where $\Phi_{0}$ and $\gamma$ are constants and $\Phi_{n}$ is the calculated $\Phi$ value shown in Figure 8 . The second term $-\gamma \sqrt{\Phi_{n}(\epsilon)-\Phi_{n}(\epsilon=0)} V_{f}\left(P_{0}\right)$ on the right-hand side of (4) represents the contribution of the nonlinearity to the overall $\Lambda$ value.

On the other hand, the relationship between the nonlinear parameter $\epsilon$ and $P_{0}$ can be expressed as follows:

$$
\epsilon=\chi\left(P_{0}-P_{\text {th }}\right)^{(m / 2)},
$$

where $\chi$ is a constant and $m$ is the order of the square root of the power difference $P_{0}-P_{\mathrm{th}} . \epsilon$ and $\chi$ correspond to the induced polarization and nonlinear susceptibility in nonlinear optics, respectively [60]. In the calculation, the author adopted $\chi=1$ and $m=2$.

By using (4), $\Phi_{0}=31.5 \mu \mathrm{s}, \gamma=3.6$, and the $\Phi_{n}$ values shown in Figure 8, the $\Lambda$ values were calculated as a function of $P_{0}$. 


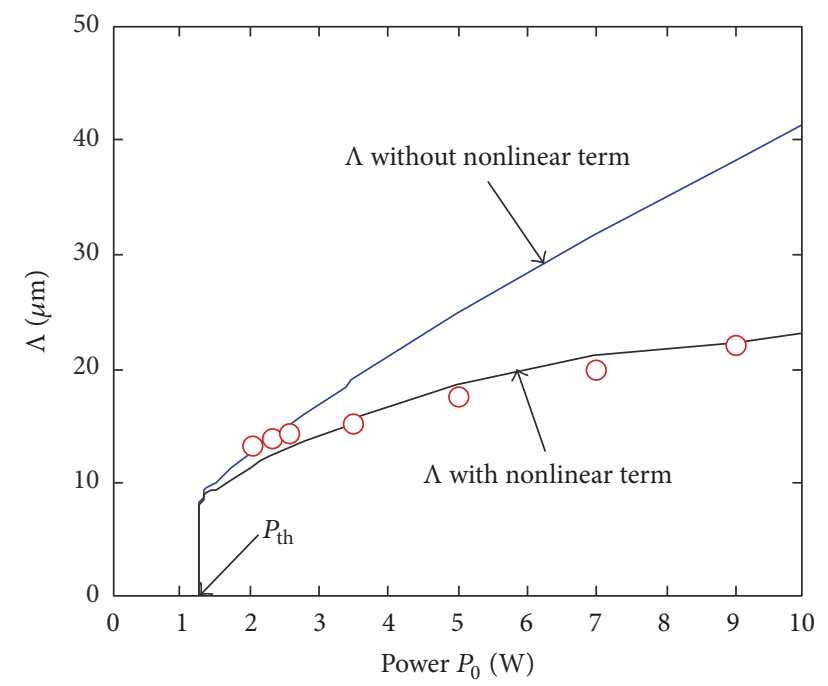

FIGURE 9: Relationship between the interval $\Lambda$ and the input power $P_{0}$. The blue and black solid lines were calculated by using (6) and (4), respectively. The red open circles are the data reported by Todoroki $[22,25]$.

The calculated results are shown in Figure 9. The blue solid line in Figure 9 was the calculation curve using the following equation:

$$
\Lambda\left(P_{0}\right)=\Phi_{0} V_{f}\left(P_{0}\right)
$$

which is the first term on the right-hand side of (4).

As shown in Figure 9, $\Lambda$ exhibits a steep rise near the threshold power $\left(P_{\text {th }}\right)$ and increases with increasing $P_{0}$. The $\Lambda$ values at $P_{0}=2.0-2.5 \mathrm{~W}$ obey (6). However, with increasing $P_{0}$, the $\Lambda$ values at $P_{0}$ of $>2.5 \mathrm{~W}$ are less than those calculated using (6) and approach the $\Lambda$ values estimated by using (4).

This may be related to the modes of fiber-fuse propagation reported by Todoroki $[22,25]$. Todoroki classified the damage to the front part of a fiber fuse into three shapes (two spheroids and a long partially cylindrical void) depending on the pump power, and the appearance of the long partially cylindrical void was observed at $P_{0}$ of $>3.5 \mathrm{~W}$ [22] or $2.3 \mathrm{~W}$ [25]. As shown in Figure 9, the distinct contribution of the nonlinearity to the overall $\Lambda$ value begins at $P_{0}$ of $2.3-3.5 \mathrm{~W}$, and the oscillatory motion of the gas plasma will change from a nearly harmonic oscillation (see Figure 3) to a relaxation one (see Figure 4 ) with increasing $P_{0}$. Therefore, the change from the spheroids of unstable and unimodal modes to the long partially cylindrical voids of the cylindrical mode may be related to the contribution of the nonlinearity.

As shown in Figures 4-6, rarefaction occurs periodically near the high-temperature peak, and the density of the rarefied gas plasma decreases over a period of $\Phi / 2$.

In what follows, the production and diffusion of $\mathrm{O}_{2}$ gas in the high-temperature core layer are described.

2.2. Oxygen Production in Optical Fiber. When gaseous $\mathrm{SiO}$ and/or $\mathrm{SiO}_{2}$ molecules are heated to high temperatures of above 5,000 K, they decompose to form $\mathrm{Si}$ and $\mathrm{O}$ atoms and

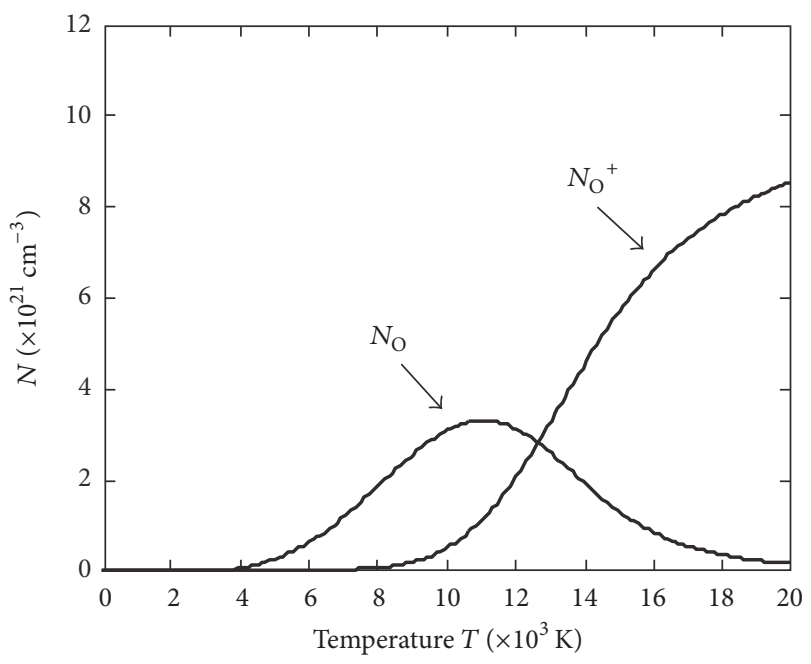

Figure 10: Temperature dependence of the number densities of $\mathrm{O}$ and $\mathrm{O}^{+}$.

finally become $\mathrm{Si}^{+}$and $\mathrm{O}^{+}$ions and electrons in the ionized gas plasma state.

In a confined core zone, and thus at high pressures, $\mathrm{SiO}_{2}$ is decomposed with the evolution of $\mathrm{SiO}$ gas or $\mathrm{Si}$ and $\mathrm{O}$ atomic gases at elevated temperatures [61]:

$$
\mathrm{SiO}_{2} \rightleftarrows \mathrm{SiO}+\left(\frac{1}{2}\right) \mathrm{O}_{2} \rightleftarrows \mathrm{Si}+2 \mathrm{O}
$$

The number densities $N_{\mathrm{SiO}}, N_{\mathrm{Si}}$, and $N_{\mathrm{O}}\left(\right.$ in $\mathrm{cm}^{-3}$ ) can be estimated using the procedure described in $[62,63]$ and the published thermochemical data [64] for $\mathrm{Si}, \mathrm{SiO}, \mathrm{O}, \mathrm{O}_{2}$, and $\mathrm{SiO}_{2}$.

The dependence of $N_{\mathrm{O}}$ on the temperature $T$ is shown in Figure 10. $N_{\mathrm{O}}$ gradually approaches its maximum value $\left(3.3 \times 10^{21} \mathrm{~cm}^{-3}\right)$ at $11,100 \mathrm{~K}$ and then decreases with further increasing $T$. This is because oxygen $(\mathrm{O})$ atoms are ionized to produce $\mathrm{O}^{+}$ions and electrons in the ionized gas plasma as follows:

$$
\mathrm{O} \rightleftarrows \mathrm{O}^{+}+\mathrm{e}^{-}
$$

The number density $N_{\mathrm{O}^{+}}$of $\mathrm{O}^{+}$ions can be estimated using the Saha equation $[63,65]$ :

$$
\frac{N_{\mathrm{O}^{+}}^{2}}{N_{\mathrm{O}}} \approx 2 \frac{\left(2 \pi m_{e} k T\right)^{3 / 2}}{h^{3}} \frac{Z_{+}}{Z_{0}} \exp \left(-\frac{I_{p}}{k_{B} T}\right),
$$

where $I_{p}(=13.61 \mathrm{eV}[66])$ is the ionization energy of a neutral $\mathrm{O}$ atom, $m_{e}$ is the electron mass, $h$ is Planck's constant, and $k_{B}$ is Boltzmann's constant. $Z_{+}$and $Z_{0}$ are the partition functions of ionized atoms and neutral atoms, respectively, and $Z_{+} \approx$ $Z_{0}$. The relationship between $N_{\mathrm{O}^{+}}$and $T$ is also shown in Figure $10 . N_{\mathrm{O}^{+}}$increases gradually at temperatures above $7,000 \mathrm{~K}$ and reaches $8.9 \times 10^{21} \mathrm{~cm}^{-3}$ at $2 \times 10^{4} \mathrm{~K}$.

It has been found that molecular oxygen is released and remains in the cavities of a damaged core layer while maintaining a relatively high pressure (about 4 atmospheres [7] 


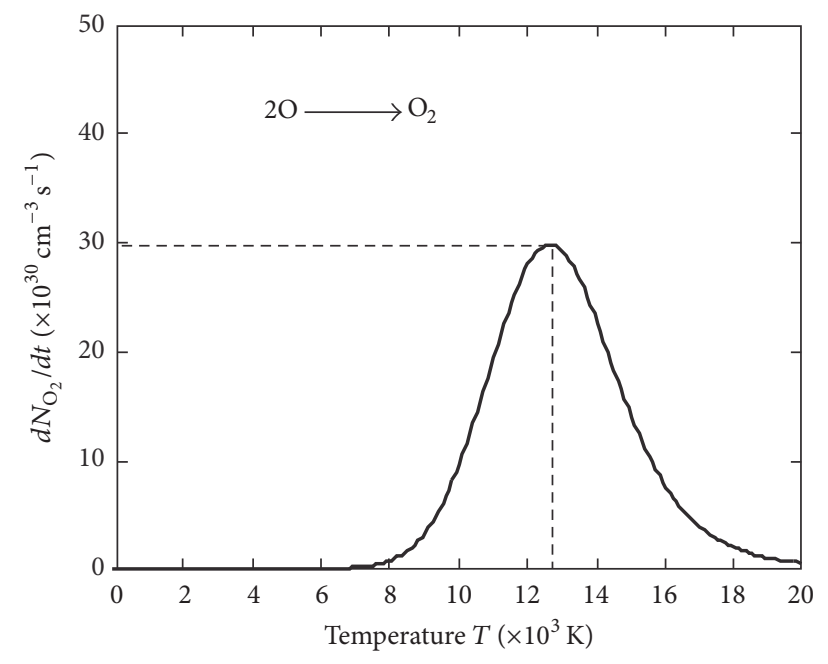

Figure 11: Temperature dependence of the production rate of $\mathrm{O}_{2}$.

or 5-10 atmospheres [19]) at room temperature. The molecular oxygen $\left(\mathrm{O}_{2}\right)$ is produced from neutral $\mathrm{O}$ atoms as follows:

$$
2 \mathrm{O} \longrightarrow \mathrm{O}_{2}
$$

The rate equation of this reaction is [67]

$$
\frac{d N_{\mathrm{O}_{2}}}{d t}=\sqrt{2} \pi \sigma^{2} \sqrt{\frac{8 R T}{\pi M_{\mathrm{O}}}} N_{\mathrm{O}}^{2} \exp \left(-\frac{E_{a}}{R T}\right),
$$

where $\sigma(=1.5 \AA)$ is half of the collision diameter, $M_{\mathrm{O}}$ (= $16.0 \times 10^{-3} \mathrm{~kg}$ ) is the atomic weight of $\mathrm{O}$, and $E_{a}$ is the activation energy. The bond energy (493.6 kJ/mol [68]) of oxygen was used for $E_{a}$.

The dependence of $d N_{\mathrm{O}_{2}} / d t$ on the temperature $T$ is shown in Figure 11. The rate of $\mathrm{O}_{2}$ production $d N_{\mathrm{O}_{2}} / d t$ exhibits its maximum value $\left(2.96 \times 10^{31} \mathrm{~cm}^{-3} \mathrm{~s}^{-1}\right)$ at $12,700 \mathrm{~K}$. This means that the oxygen molecules are produced most effectively at $12,700 \mathrm{~K}$.

Figure 12 shows the temperature distribution of the hightemperature front along the $z$ direction at $t=3 \mathrm{~ms}$ after the incidence of $1.8 \mathrm{~W}$ laser light for $\mathrm{IA}=8 \mathrm{~dB}$. In this figure, the center of the high-temperature front is set at $L=0 \mu \mathrm{m}$. In Figure 12, $\Delta L_{s}$, which is about $36.5 \mu \mathrm{m}$, is the distance between the high-temperature peak $(L=0 \mu \mathrm{m})$ and the location with a temperature of $12,700 \mathrm{~K}$.

This $\Delta L_{s}$ can be converted into the time lag $\Delta \tau_{s}$ from the passage of the high-temperature front as follows:

$$
\Delta \tau_{s}=\frac{\Delta L_{s}}{V_{f}} .
$$

It is expected that the $\mathrm{O}_{2}$ molecular gas in the ionized gas plasma will be observed most frequently after a time lag of $\Delta \tau_{s}$ from the passage of the high-temperature peak. If the produced $\mathrm{O}_{2}$ gas diffuses into the rarefied part of the oscillatory variation in density shown in Figures 4-6, periodic cavities containing some of the oxygen molecules will be formed (see below).

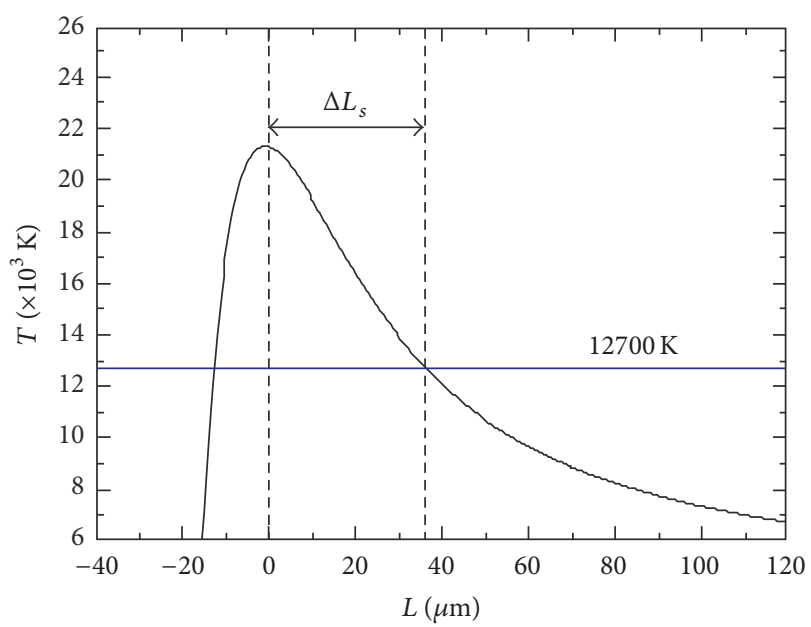

FIgURE 12: Temperature distribution of the high-temperature front versus the length along the $z$ direction at $t=3 \mathrm{~ms}$ after the incidence of $1.8 \mathrm{~W}$ laser light for IA $=8 \mathrm{~dB}$. The center of the high-temperature front is set at $L=0 \mu \mathrm{m}$.

When $V_{f}=1 \mathrm{~m} / \mathrm{s}$, the $\Delta \tau_{s}$ values were estimated at a time of $t=1.55-3 \mathrm{~ms}$ after the incidence of $1.8 \mathrm{~W}$ laser light for $\mathrm{IA}=8 \mathrm{~dB}$. The calculated $\Delta \tau_{s}$ values are plotted in Figure 13 as a function of $t$. The fiber-fuse phenomenon was initiated at $t=1.5 \mathrm{~ms}$ (see Figure 14 in [54]). As shown in Figure 13, $\Delta \tau_{s}$ increases rapidly with increasing $t$ immediately after the fiber fuse is initiated and reaches a constant value $(36.5 \mu \mathrm{s})$ at $t>1.65 \mathrm{~ms}$. This value is in reasonable agreement with the experimental values $(20-70 \mu \mathrm{s})$ reported by Dianov and coworkers $[29,30]$.

2.3. Diffusion Length of Oxygen Gas. The $\mathrm{O}_{2}$ gas produced near the high-temperature front diffuses from the compressed part into the rarefied part of the oscillatory variation during a small period $\Phi$ of $10-30 \mu$ s (see Figure 9 ).

The diffusion coefficient $D$ of the $\mathrm{O}_{2}$ gas is given by [67]

$$
D=\frac{2}{3 \pi \sigma^{2} N_{\mathrm{O}_{2}}} \sqrt{\frac{R T}{\pi M_{\mathrm{O}_{2}}}}
$$

where $M_{\mathrm{O}_{2}}\left(=32.0 \times 10^{-3} \mathrm{~kg}\right)$ is the molecular weight of $\mathrm{O}_{2}$ gas. As $N_{\mathrm{O}_{2}}$ is smaller than $N_{\mathrm{O}} / 2, N_{\mathrm{O}_{2}} \approx N_{\mathrm{O}} / 2$ is assumed in the calculation.

The mean square of the displacement $\Delta \bar{z}^{2}$ along the $z$ direction of the optical fiber can be estimated from $D$ and time $t$ as follows [69]:

$$
\Delta \bar{z}^{2}=2 D t
$$

The $\Delta \bar{z}$ values at $T=12,700 \mathrm{~K}$ were estimated using (13) and (14). When $t=20 \mu \mathrm{s}$, the calculated $\Delta \bar{z}$ value is given by

$$
\Delta \bar{z}= \pm 16.7 \mu \mathrm{m}
$$

This $\Delta \bar{z}$ value is of the same order as the observed periodic void interval (13-22 $\mu \mathrm{m})$ [55].

Figure 14 shows a schematic view of the diffusion of the $\mathrm{O}_{2}$ gas from the compressed part into the rarefied part in 


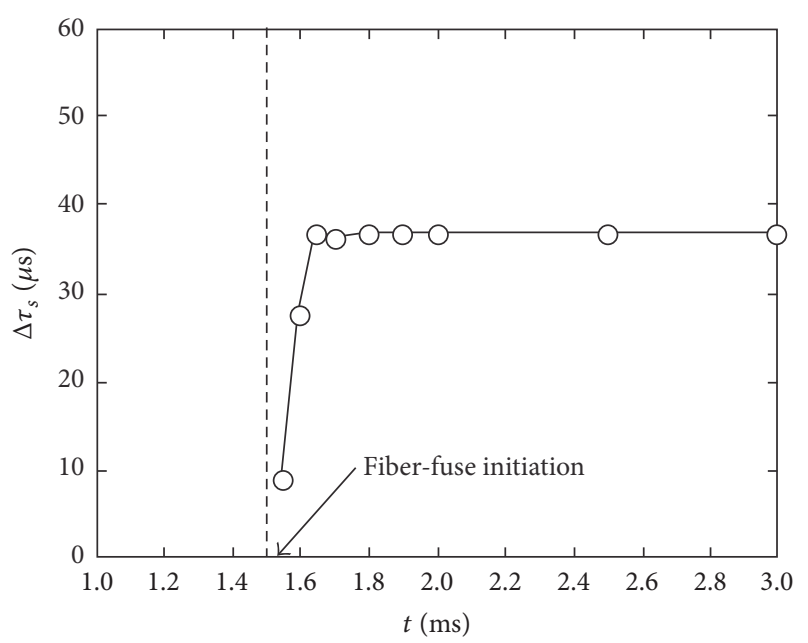

FIGURE 13: $\Delta \tau_{s}$ values versus $t$ after the incidence of $1.8 \mathrm{~W}$ laser light for IA $=8 \mathrm{~dB}$.

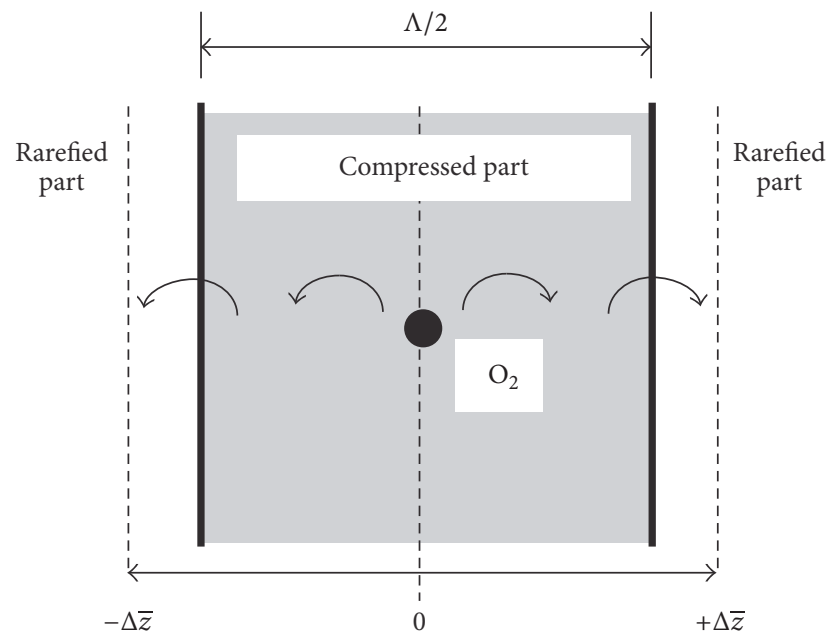

Figure 14: Schematic view of diffusion of oxygen gas from the compressed part into the rarefied part in the high-temperature plasma.

the high-temperature plasma. If the absolute value of $\Delta \bar{z}$ is larger than half of the interval $\Lambda$ between the periodic rarefied parts, many of the $\mathrm{O}_{2}$ molecules produced in the compressed part can move into the rarefied part during the period $\Phi$ $(10-30 \mu \mathrm{s})$ of the relaxation oscillation. This $\mathrm{O}_{2}$ gas will form temporary microscopic voids that can constitute the nuclei necessary for growth into macroscopic bubbles [70].

As described above, the nonlinear oscillation model was able to phenomenologically explain both the densification of the core material and the formation of periodic cavities in the core layer as a result of the relaxation oscillation and the formation of $\mathrm{O}_{2}$ gas near the high-temperature front.

\section{Conclusion}

The evolution of a fiber fuse in a single-mode optical fiber was studied theoretically. To clarify both the silica-glass densification and cavity formation, which are observed in fiber-fuse propagation, we investigated a nonlinear oscillation model using the Van Der Pol equation. This model was able to phenomenologically explain both the densification of the core material and the formation of periodic cavities in the core layer as a result of a relaxation oscillation.

Keen and Fletcher reported that the method of "asynchronous quenching of a Van Der Pol oscillator" might be used to suppress (or quench) a plasma instability [37]. This method relies on driving the previously existing Van Der Pol oscillator (or instability) at a high frequency $\omega$ such that $\omega \gg \omega_{0}$, where $\omega_{0}$ is the frequency of the Van Der Pol oscillator. With increasing the drive amplitude, the system behaves as if the previously existing relaxation oscillation $\left(\omega_{0}\right)$ was destroyed (or quenched) by the asynchronous action of this frequency $(\omega)$.

In the fiber-fuse experiment, the driving frequency might be related to the optical pulse widths of the high-power laser. It will be necessary to clarify the relationship between the driving frequency and the suppression of cavities in detail in the fiber-fuse experiments.

This nonlinear oscillation model including the relaxation oscillation is a phenomenological model, and the relationship between the nonlinearity parameters $(\epsilon, \beta)$ and the physical properties observed in the fiber-fuse experiments is unknown. Therefore, to clarify this relationship, further quantitative investigation is also necessary.

\section{Appendix}

\section{A. Electrostatic Interaction between Charged Surface and Plasma}

In a confined core zone, and thus at a high pressure, $\mathrm{SiO}_{2}$ is decomposed with the evolution of $\mathrm{SiO}$ gas or $\mathrm{Si}$ and $\mathrm{O}$ atomic gases at elevated temperatures, as described above. When the $\mathrm{Si}$ and $\mathrm{O}$ atomic gases are heated to high temperatures of above $3,000 \mathrm{~K}(\mathrm{Si})$ and $4,000 \mathrm{~K}(\mathrm{O})$, they are ionized to produce $\mathrm{Si}^{+}$and $\mathrm{O}^{+}$ions and electrons in the ionized gas plasma state:

$$
\mathrm{Si}+\mathrm{O} \rightleftarrows \mathrm{Si}^{+}+\mathrm{O}^{+}+2 \mathrm{e}^{-} .
$$

If thermally produced electrons in the plasma are not bound to positive species $\left(\mathrm{Si}^{+}\right.$or $\mathrm{O}^{+}$ions), they can move freely in the plasma under the action of the alternating electric field of the light wave. Such free diffusion is possible only in the limiting case of very low charge densities. However, as shown in Figure 10 and also Figure 1 in [63], the densities of $\mathrm{Si}^{+}$and $\mathrm{O}^{+}$ions and electrons are reasonably large above $1 \times 10^{4} \mathrm{~K}$. At high charge densities, it is known that the positive and negative species diffuse at the same rate. This phenomenon, proposed by Schottky [71], is called ambipolar diffusion [72, 73]. Ambipolar diffusion is the diffusion of positive and negative species owing to their interaction via an electric field (space-charge field). In plasma physics, ambipolar diffusion is closely related to the concept of quasineutrality.

Some electrons arrive at the surface of melted silica glass, and they attach to oxygen atoms on the surface 
because oxygen atoms have a high electron affinity [74]. As a result, a negatively charged surface, which was proposed by Yakovlenko [32], may be formed as shown in Figure 15.

However, the negative charges on the surface will immediately be balanced by an equal number of oppositely charged $\mathrm{Si}^{+}$and $\mathrm{O}^{+}$ions because these positive ions move together with the electrons as a result of ambipolar diffusion. In this way, an atmosphere of ions is formed in the rapid thermal motion close to the surface. This ionic atmosphere is known as the diffuse electric double layer [75].

The thickness $\delta_{0}$ of the double layer is approximately $1 / \kappa$, which is the characteristic length known as the Debye length. The parameter $\kappa$ is given in terms of $N_{e}$ and $T$ as follows [73]:

$$
\kappa^{2}=\frac{2 N_{\mathrm{e}} e^{2}}{\varepsilon_{0} k_{B} T}
$$

where $e$ is the charge of an electron and $\varepsilon_{0}$ is the dielectric constant of vacuum. When $T=1 \times 10^{4} \mathrm{~K}$ and $N_{e}=2.2 \times$ $10^{20} \mathrm{~cm}^{-3}$. Using these values and (A.2), the thickness $\delta_{0}$ of the double layer at $1 \times 10^{4} \mathrm{~K}$ was estimated to be about $3.3 \times$ $10^{-10} \mathrm{~m}$

The cross section of the high-temperature plasma in the optical fiber can be schematically illustrated using the double layers as shown in Figure 16.

In the central domain of the high-temperature plasma, electrically neutral atoms ( $\mathrm{Si}$ and $\mathrm{O}$ ) and charged species $\left(\mathrm{Si}^{+}, \mathrm{O}^{+}\right.$, and $\left.e^{-}\right)$exist. As the charged species are balanced, electrical neutrality is achieved in the domain. Moreover, the dimensions of the domain are almost equal to those of the high-temperature plasma excluding the very thin ( $\AA$ order) electric double layers at the surface of the melted silica glass.

\section{B. Nonlinear Parameter $\beta$ in Van Der Pol Equation}

The dynamical behavior of the perturbed density $\rho_{1}$ resulting from fiber-fuse propagation can be represented by the Van Der Pol equation:

$$
\ddot{\rho}_{1}-\epsilon\left(1-\beta \rho_{1}^{2}\right) \dot{\rho}_{1}+\omega_{0}^{2} \rho_{1}=0
$$

where $\ddot{\rho}_{1}=d^{2} \rho_{1} / d t^{2}, \dot{\rho}_{1}=d \rho_{1} / d t$, and $\epsilon$ and $\beta$ are the nonlinear parameters.

If the solution of (B.1) is written,

$$
\rho_{1}=A \cos \left(\omega_{0} t+\varphi\right)
$$

where the amplitude $A$ and phase $\varphi$ are slowly varying functions, then the $A$ obeys the following equation:

$$
A^{2}=\rho_{1}^{2}+\left(\frac{\dot{\rho}_{1}}{\omega_{0}}\right)^{2}
$$

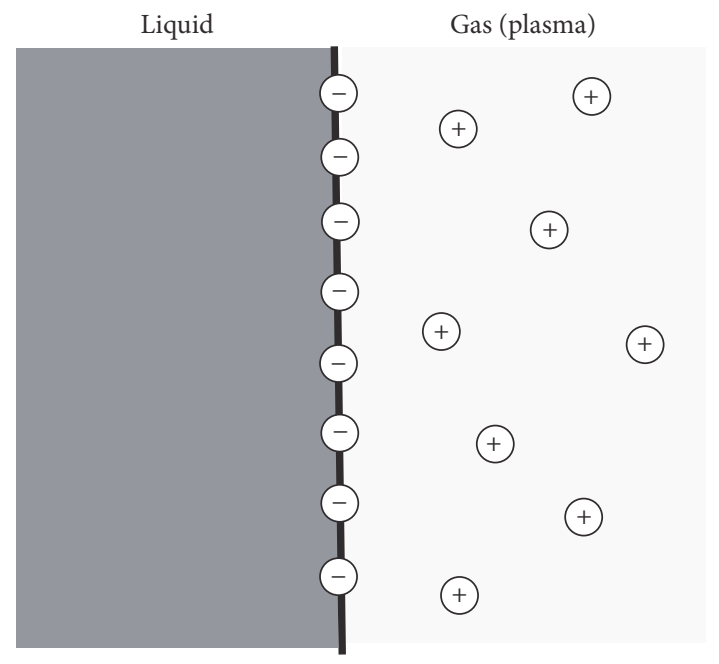

FIGURE 15: Schematic view of the negatively charged surface and ionic atmosphere.

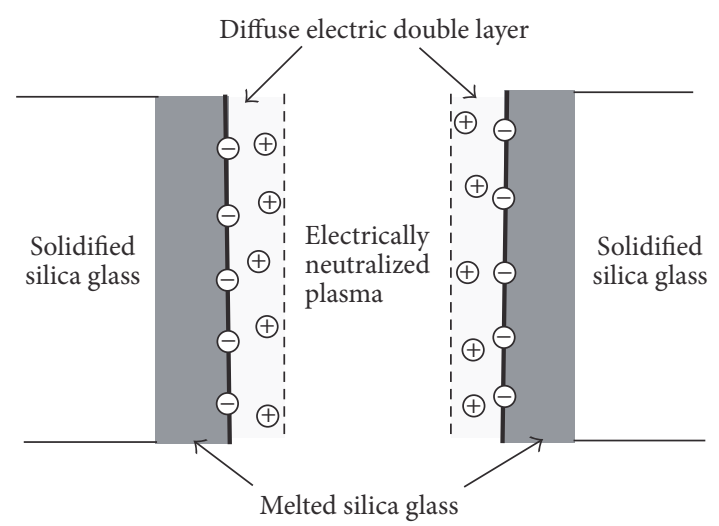

FIgURE 16: Schematic view of the cross section of the hightemperature plasma in the optical fiber.

Differentiating (B.3), we get

$$
\begin{aligned}
\dot{A}= & \frac{\dot{\rho}_{1}}{\omega_{0}^{2} A}\left(\ddot{\rho}_{1}+\omega_{0}^{2} \rho_{1}\right)=\frac{\dot{\rho}_{1}}{\omega_{0}^{2} A}\left[\epsilon\left(1-\beta \rho_{1}^{2}\right) \dot{\rho}_{1}\right] \\
= & \frac{\epsilon}{\omega_{0}^{2} A}\left(\dot{\rho}_{1}^{2}\right)-\frac{\epsilon \beta}{\omega_{0}^{2} A} \rho_{1}^{2}\left(\dot{\rho}_{1}^{2}\right) \\
= & \epsilon A \sin ^{2}\left(\omega_{0} t+\varphi\right) \\
& -\epsilon \beta A^{3} \sin ^{2}\left(\omega_{0} t+\varphi\right) \cos ^{2}\left(\omega_{0} t+\varphi\right) \\
= & \frac{\epsilon}{2} A\left[1-\cos \left(2 \omega_{0} t+2 \varphi\right)\right] \\
& -\frac{\epsilon \beta}{8} A^{3}\left[1-\cos \left(4 \omega_{0} t+4 \varphi\right)\right] .
\end{aligned}
$$

Because of the slowly varying property of $A$, the oscillatory terms $A \cos \left(2 \omega_{0} t+2 \varphi\right)$ and $A^{3} \cos \left(4 \omega_{0} t+4 \varphi\right)$ on the 
right-hand side of (B.4) are averaged out every cycle and can be discarded [76], so that (B.4) is reduced to

$$
\dot{A} \simeq \frac{\epsilon}{2} A-\frac{\epsilon \beta}{8} A^{3} \simeq \frac{\epsilon}{2} A\left(1-\frac{\beta}{4} A^{2}\right) .
$$

The maximum value of $A, A_{m}$, is obtained under the condition of $\dot{A}=0$. To satisfy this condition, $A_{m}$ obeys

$$
A_{m}=\frac{2}{\sqrt{\beta}} \text {. }
$$

This means that the nonlinear parameter $\beta$ determines the maximun amplitude of $\rho_{1}$. In the calculation, we used $\beta=6.5$, which corresponds to $A_{m} \simeq 0.8$.

\section{Conflicts of Interest}

The author declares that there are no conflicts of interest regarding the publication of this paper.

\section{References}

[1] A. Asano, T. Kobayashi, E. Yoshida, and Y. Miyamoto, "Ultrahigh capacity optical transmission technologies for $100 \mathrm{Tbit} / \mathrm{s}$ optical transport networks," IEICE Transactions on Communications, vol. 94, no. 2, pp. 400-408, 2011.

[2] M. Nakazawa, "Evolution of EDFA from single-core to multicore and related recent progress in optical communication," Optical Review, vol. 21, no. 6, pp. 862-874, 2014.

[3] T. Morioka, "New generation optical infrastructure technologies: 'EXAT initiative' towards 2020 and beyond," in Proceedings of the 14th OptoElectronics and Communications Conference (OECC '09), pp. 1-2, IEEE, Hong Kong, July 2009.

[4] D. J. Richardson, J. M. Fini, and L. E. Nelson, "Space-division multiplexing in optical fibres," Nature Photonics, vol. 7, no. 5, pp. 354-362, 2013.

[5] H. Takara, A. Asano, T. Kobayashi et al., "Proceedings of the 1.01- $\mathrm{Pb} / \mathrm{s}(12 \mathrm{SDM} / 222 \mathrm{WDM} / 456 \mathrm{~Gb} / \mathrm{s})$ crosstalk-managed transmission with $91.4-\mathrm{b} / \mathrm{s} / \mathrm{Hz}$ aggregate spectral efficiency," in European Conference and Exhibition on Optical Communication, ECEOC 2012, September 2012.

[6] R. Kashyap and K. J. Blow, "Observation of catastrophic selfpropelled self-focusing in optical fibres," Electronics Letters, vol. 24, no. 1, pp. 47-49, 1988.

[7] R. Kashyap, "Self-propelled self-focusing damage in optical fibres," in Proceedings of the 10th Int. Conf. Lasers, pp. 859-866, 1988.

[8] D. P. Hand and P. S. Russell, "Solitary thermal shock waves and optical damage in optical fibers: the fiber fuse," Optics Letters, vol. 13, no. 9, pp. 767-769, 1988.

[9] D. P. Hand and P. St. J. Russell, "Soliton-like thermal shockwaves in optical fibers: origin of periodic damage tracks," in European Conference on Optical Communication, pp. 111-114, 1988.

[10] P. André, A. Rocha, F. Domingues, and M. Facão, “Thermal effects in optical fibres," in Developments in Heat Transfer, M. A. D. Bernardes, Ed., chapter 1, pp. 1-20, InTech, Rijeka, Croatia, 2011.

[11] S. Todoroki, "Fiber fuse propagation behavior," in Selected Topics on Optical Fiber Technology, M. Yasin, S. W. Harun, and
H. Arof, Eds., chapter 20, pp. 551-570, InTech, Rijeka, Croatia, 2012.

[12] R. Kashyap, "The fiber fuse-from a curious effect to a critical issue: a 25th year retrospective," Optics Express, vol. 21, no. 5, pp. 6422-6441, 2013.

[13] S. Todoroki, Fiber Fuse: Light-Induced Continuous Breakdown of Silica Glass Optical Fiber, NIMS Monographs, Springer, Tokyo, 2014.

[14] Y. Shuto, "Simulation of fiber fuse phenomenon in single-mode optical fibers," in Advances in Optical Fiber Technology, M. Yasin, H. Arof, and S. W. Harun, Eds., chapter 5, pp. 159-197, InTech, Rijeka, Croatia, 2014.

[15] S. Todoroki, "Quantitative evaluation of fiber fuse initiation probability in typical single-mode fibers," in Proceedings of the Optical Fiber Communication Conference, OSA Technical Digest, Optical Society of America, 2015.

[16] S.-I. Todoroki, "Quantitative evaluation of fiber fuse initiation with exposure to arc discharge provided by a fusion splicer," Scientific Reports, vol. 6, no. article 25366, 2016.

[17] E. M. Dianov, I. A. Bufetov, and A. A. Frolov, "Destruction of silica fiber cladding by the fuse effect," Optics Letters, vol. 29, no. 16, pp. 1852-1854, 2004.

[18] K. Kurokawa and N. Hanzawa, "Fiber fuse propagation and its suppression in hole-assisted fibers," IEICE Transactions on Communications, vol. 94, no. 2, pp. 384-391, 2011.

[19] E. M. Dianov, V. M. Mashinsky, V. A. Myzina, Y. S. Sidorin, A. M. Streltsov, and A. V. Chickolini, "Change of refractive index profile in the process of laser-induced fibre damage," Soviet Lightwave Communications, vol. 2, no. 4, pp. 293-299, 1992.

[20] D. D. Davis, S. C. Mettler, and D. J. DiGiovanni, "Experimental investigation of the fiber fuse," Proceedings of the Society of Photo-Optical Instrumentation Engineers, vol. 2714, pp. 202-210, 1995.

[21] D. D. Davis, S. C. Mettler, and D. J. DiGiovanni, "A comparative evaluation of fiber fuse models," Proceedings of the Society of Photo-Optical Instrumentation Engineers, vol. 2966, pp. 592606, 1996.

[22] S.-I. Todoroki, "Origin of periodic void formation during fiber fuse," Optics Express, vol. 13, no. 17, pp. 6381-6389, 2005.

[23] S.-I. Todoroki, "In situ observation of modulated light emission of fiber fuse synchronized with void train over hetero-core splice point," PLoS ONE, vol. 3, no. 9, article e3276, 2008.

[24] F. Domingues, A. R. Frias, P. Antunes, A. O. P. Sousa, R. A. S. Ferreira, and P. S. André, "Observation of fuse effect discharge zone nonlinear velocity regime in erbium-doped fibres," Electronics Letters, vol. 48, no. 20, pp. 1295-1296, 2012.

[25] S. Todoroki, "Fiber fuse propagation modes in typical singlemode fibers," in Proceedings of the Optical Fiber Communication Conference, OSA Technical Digest, Optical Society of America, 2013.

[26] P. F. C. Antunes, M. F. F. Domingues, N. J. Alberto, and P. S. André, "Optical fiber microcavity strain sensors produced by the catastrophic fuse effect," IEEE Photonics Technology Letters, vol. 26, no. 1, pp. 78-81, 2014.

[27] G.-R. Lin, M. D. Baiad, M. Gagne, W.-F. Liu, and R. Kashyap, "Harnessing the fiber fuse for sensing applications," Optics Express, vol. 22, no. 8, pp. 8962-8969, 2014.

[28] M. F. F. De Fátima F.domingues, T. B. Brito Paixão, E. F. T. Mesquita et al., "Liquid hydrostatic pressure optical sensor based on micro-cavity produced by the catastrophic fuse effect," IEEE Sensors Journal, vol. 15, no. 10, pp. 5654-5658, 2015. 
[29] I. A. Bufetov, A. A. Frolov, E. M. Dianov, V. E. Frotov, and V. P. Efremov, "Dynamics of fiber fuse propagation," in Proceedings of the Optical Fiber Communication Conference, OSA Technical Digest of OFC/NFOEC 2005, Optical Society of America, 2005.

[30] E. M. Dianov, V. E. Fortov, I. A. Bufetov et al., "High-speed photography, spectra, and temperature of optical discharge in silica-based fiberss," IEEE Photonics Technology Letters, vol. 18, no. 6, pp. 752-754, 2006.

[31] R. M. Atkins, P. G. Simpkins, and A. D. Yablon, "Track of a fiber fuse: a Rayleigh instability in optical waveguides," Optics Letters, vol. 28, no. 12, pp. 974-976, 2003.

[32] S. I. Yakovlenko, "Plasma behind the front of a damage wave and the mechanism of laser-induced production of a chain of caverns in an optical fibre," Quantum Electronics, vol. 34, no. 8, pp. 765-770, 2004.

[33] S. I. Yakovlenko, "Mechanism for the void formation in the bright spot of a fiber fuse," Laser Physics, vol. 16, no. 3, pp. 474476, 2006.

[34] R. H. Abrams Jr., E. J. Yadlowsky, and H. Lashinsky, "Periodic pulling and turbulence in a bounded plasma," Physical Review Letters, vol. 22, no. 7, pp. 275-278, 1969.

[35] T. H. Stix, "Finite-amplitude collisional drift waves," Physics of Fluids, vol. 12, no. 3, pp. 627-639, 1969.

[36] B. E. Keen and W. H. W. Fletcher, "Suppression and enhancement of an ion-sound instability by nonlinear resonance effects in a plasma," Physical Review Letters, vol. 23, no. 14, pp. 760-763, 1969.

[37] B. E. Keen and W. H. W. Fletcher, "Suppression of a plasma instability by the method of 'asynchronous quenching,' Physical Review Letters, vol. 24, no. 4, pp. 130-134, 1970.

[38] B. E. Keen, "Interpretation of experiments on feedback control of a 'drift- type' instability,' Physical Review Letters, vol. 24, no. 6, pp. 259-262, 1970.

[39] A. V. Shutko, "Finite amplitude ion acoustic waves in an unstable plasma," Soviet Physics JETP, vol. 30, no. 2, pp. 248251, 1970.

[40] Y. Nakamura, "Suppression of two-stream instability by beam modulation," Journal of the Physical Society of Japan, vol. 28, no. 5, pp. 1315-1321, 1970.

[41] B. E. Keen and W. H. W. Fletcher, "Remote feedback stabilization of the ion-sound instability by a modulated source at the electron-cyclotron resonance frequency," Physical Review Letters, vol. 25, no. 6, pp. 350-353, 1970.

[42] B. E. Keen and W. H. W. Fletcher, "Measurement of growth rate, non-linear saturation coefficients, and mode-mode coupling coefficients of a 'Van der Pol' plasma instability,' Journal of Physics D: Applied Physics, vol. 3, no. 12, article 315, pp. 1868$1885,1970$.

[43] Y. Nakamura, "Suppression and excitation of electron oscillation in a beam-plasma system," Journal of the Physical Society of Japan, vol. 31, no. 1, pp. 273-279, 1971.

[44] B. E. Keen and W. H. W. Fletcher, "Nonlinear plasma instability effects for subharmonic and harmonic forcing oscillations," Journal of Physics A: Mathematical and General, vol. 5, no. 1, article 020, pp. 152-165, 1972.

[45] R. W. Boswell, P. J. Christiansen, and C. R. Salter, "Non linear effects in an R.F. plasma," Physics Letters A, vol. 38, no. 2, pp. 67-68, 1972.

[46] R. Tavzes and M. Čerček, "Frequency entrainment of a drift instability by nonlinear effects in a plasma," Physics Letters A, vol. 43, no. 2, pp. 99-100, 1973.
[47] P. DeNeef and H. Lashinsky, "Van der Pol model for unstable waves on a beam-plasma system," Physical Review Letters, vol. 31, no. 17, pp. 1039-1041, 1973.

[48] B. E. Keen and W. H. W. Fletcher, "The ion-sound instability and its associated multi-mode phenomena," Journal of Physics D: Applied Physics, vol. 6, no. 14, pp. 1684-1698, 1973.

[49] P. Michelsen, H. L. Pécseli, J. Juul Rasmussen, and R. Schrittwieser, "The current-driven, ion-acoustic instability in a collisionless plasma," Plasma Physics, vol. 21, no. 1, article 005, pp. 61-73, 1979.

[50] A. Buragohain, J. Chutia, and Y. Nakamura, "Mode suppression and period-doubling cascade in a double-plasma device," Physics Letters A, vol. 163, no. 5-6, pp. 425-428, 1992.

[51] T. Gyergyek, M. Čerček, N. Jelić, and M. Stanojević, "Mode suppression of a two-dimensional potential relaxation instability in a weakly magnetized discharge plasma," Physics Letters A, vol. 177, no. 1, pp. 54-60, 1993.

[52] T. Klinger, A. Piel, F. Seddighi, and C. Wilke, "Van der Pol dynamics of ionization waves," Physics Letters A, vol. 182, no. 2-3, pp. 312-318, 1993.

[53] B. Van Der Pol, "Technical papers: the nonlinear theory of electric oscillations," Proceedings of the Institute of Radio Engineers, vol. 22, no. 9, pp. 1051-1086, 1934.

[54] Y. Shuto, "End face damage and fiber fuse phenomena in singlemode fiber-optic connectors," Journal of Photonics, vol. 2016, Article ID 2781392, 11 pages, 2016.

[55] S. Todoroki, Fiber Fuse: Light-Induced Continuous Breakdown of Silica Glass Optical Fiber, NIMS Monographs, chapter 3, Springer, Tokyo, Japan, 2014.

[56] Y. Shuto, S. Yanagi, S. Asakawa, M. Kobayashi, and R. Nagase, "Fiber fuse phenomenon in step-index single-mode optical fibers," IEEE Journal of Quantum Electronics, vol. 40, no. 8, pp. 1113-1121, 2004.

[57] M. Facão, A. M. Rocha, and P. S. De Brito André, "Traveling solutions of the fuse effect in optical fibers," Journal of Lightwave Technology, vol. 29, no. 1, pp. 109-114, 2011.

[58] E. D. Bumarin and S. I. Yakovlenko, "Temperature distribution in the bright spot of the optical discharge in an optical fiber," Laser Physics, vol. 16, no. 8, pp. 1235-1241, 2006.

[59] S.-I. Todoroki, “Threshold power reduction of fiber fuse propagation through a white tight-buffered single-mode optical fiber," IEICE Electronics Express, vol. 8, no. 23, pp. 1978-1982, 2011.

[60] R. W. Boyd, Nonlinear Optics, chapter 1, Academic Press, New York. NY, USA, 1992.

[61] H. L. Schick, "A thermodynamic analysis of the hightemperature vaporization properties of silica," Chemical Reviews, vol. 60, no. 4, pp. 331-362, 1960.

[62] Y. Shuto, "Heat conduction modeling of fiber fuse in singlemode optical fibers," Journal of Photonics, vol. 2014, Article ID 645207, 11 pages, 2014.

[63] Y. Shuto, "Evaluation of high-temperature absorption coefficients of ionized gas plasmas in optical fibers," IEEE Photonics Technology Letters, vol. 22, no. 3, pp. 134-136, 2010.

[64] JANAF Thermochemical Tables, U.S. Department of Commerce and National Bureau of Standards, 2nd edition, 1971.

[65] M. N. Saha, "Ionization in solar chromosphere," Philos. Mag, vol. 40, no. 238, pp. 472-488, 1920.

[66] C. Kittel, Introduction to Solid State Physics, chapter 3, John Wiley \& Sons, Inc., New York, NY, USA, 7th edition, 1996.

[67] G. W. Castellan, Physical Chemistry, chapter 33, Addison-Wesley Publishing Co., Inc., Boston, 3rd edition, 1983. 
[68] Chemical Data Book, Chemical Society of Japan, Tokyo, 3rd edition, 1984, Chap. 9,.

[69] W. J. Moore, Physical Chemistry, chapter 4, Prentice-Hall, Inc., Princeton, 4th edition, 1972.

[70] C. E. Brennen, Cavitation and Bubble Dynamics, chapter 1, Cambridge University Press, New York, NY, USA, 2014.

[71] W. Schottky, "Diffusionstheorie der positiven Säule," Physik Z, vol. 25, pp. 635-640, 1924.

[72] W. P. Allis and D. J. Rose, "The transition from free to ambipolar diffusion," Physical Review, vol. 93, no. 1, pp. 84-93, 1954.

[73] A. V. Phelps, "Diffusion of charged particles in collisional plasmas. Free and ambipolar diffusion at low and moderate pressures," Journal of Research of the National Institute of Standards and Technology, vol. 95, no. 4, pp. 407-431, 1990.

[74] S. Ohtori, T. Sekiguchi, and T. Kawano, Theory of Discharged Gases, chapter 2, Ohmsha Inc., Tokyo, Japan, 1969.

[75] J. N. Israelachvili, Intermolecular and Surface Forces, chapter 12, Academic Press, Ltd., London, England, 2nd edition, 1992.

[76] T. Kawakubo and S. Kabashima, "Stochastic processes in selfexcited oscillation," Journal of the Physical Society of Japan, vol. 37, no. 5, pp. 1199-1203, 1974. 


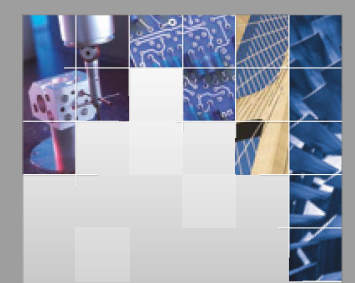

\section{Enfincering}
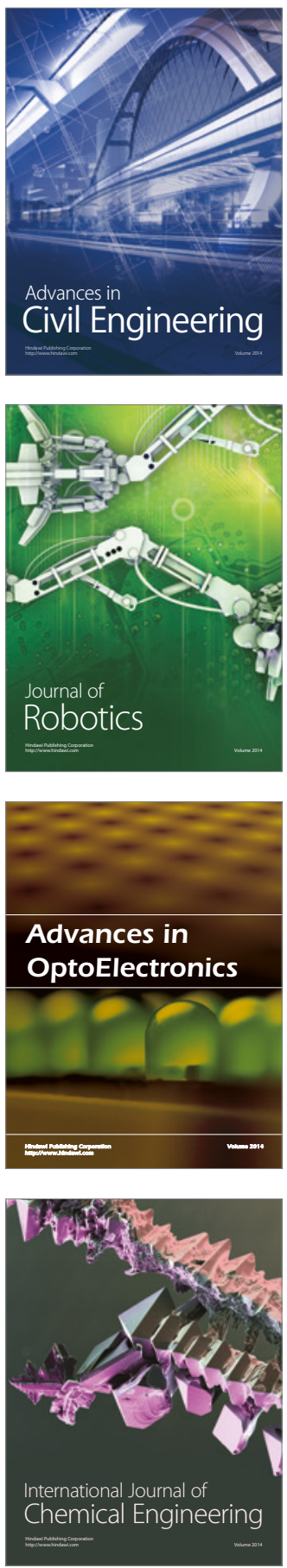

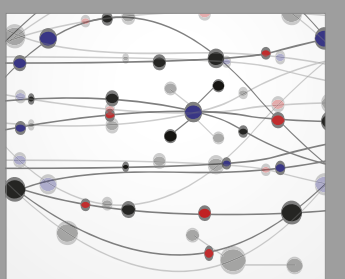

The Scientific World Journal

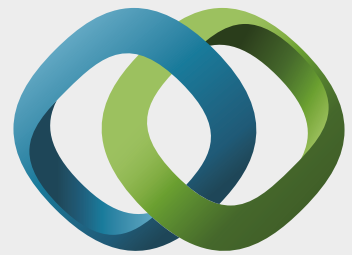

\section{Hindawi}

Submit your manuscripts at

https://www.hindawi.com
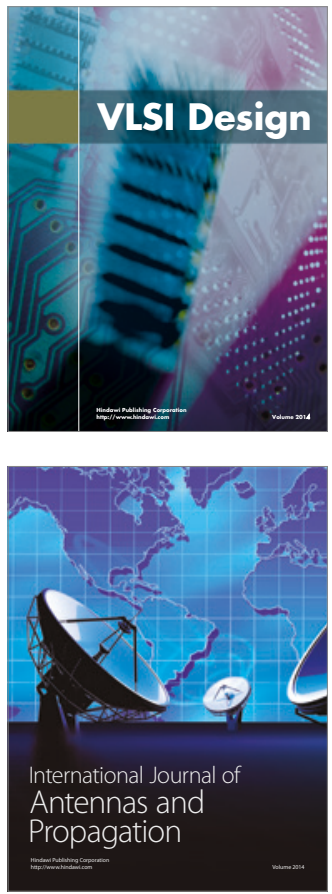

\section{Rotating}

Machinery
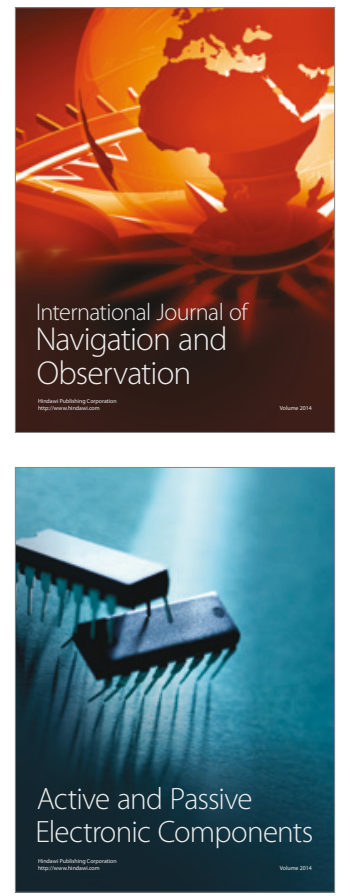
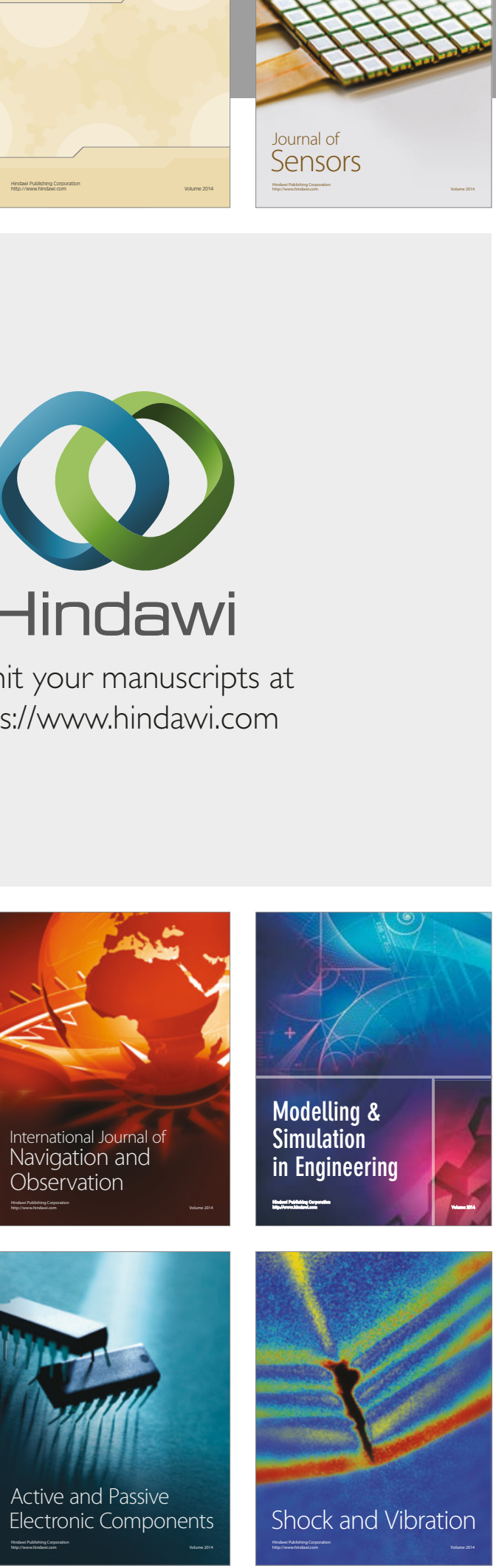
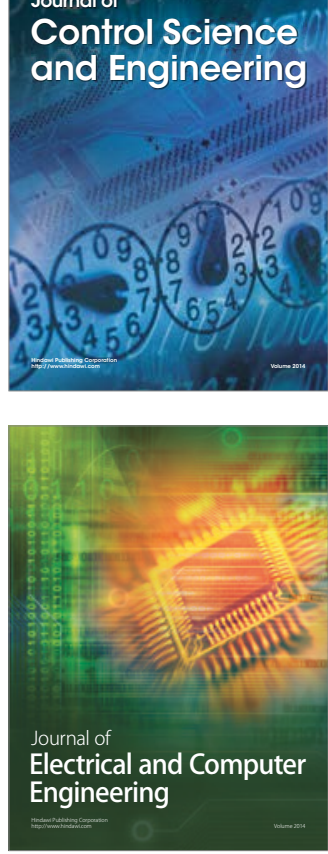

Distributed

Journal of

Control Science

and Engineering
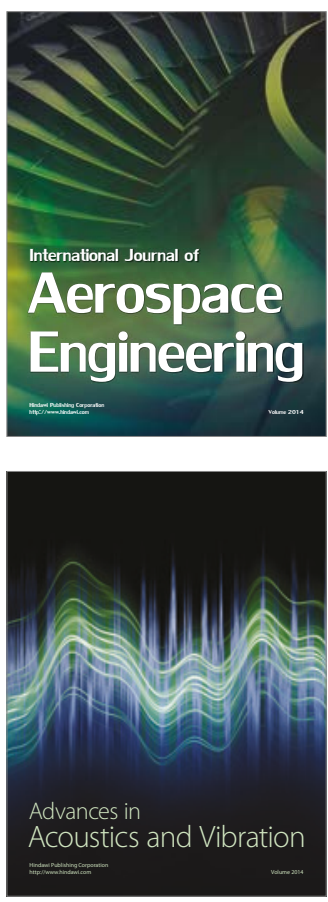

Sensor Networks 